THE HYDRATION OF THE FIBRES OF SOAP CURD.

PART I. 1369

\title{
CLVII.-The Hydration of the Fibres of Soap Curd. Part I. The Degree of Hydration determined in Experiments on Sorption and Salting Out.
}

\section{By James Witliam McBain and Herbert Ernest Martin.}

IN recent communications from this laboratory it has been shown that soap curds consist of a felt of microscopic or ultramicroscopic fibres of hydrated neutral soap enmeshing sols or gels of soap or solutions of any electrolyte present.

In a previous communication ( $T ., 1919,115,1300)$ an attempt was made to determine the degree of hydration of the soap which forms the curd fibres. The method was based on the observation that when soap is salted out in the presence of free sodium hydroxide the concentration of the latter is thereby increased. This can be explained as being due to hydration of the curd fibres, which abstracts some of the solvent from solution, and on making the further assumption that no sodium hydroxide is sorbed by the fibres, a quantitative estimate of their hydration was afforded. The experimental difficulties involved in the use of sodium hydroxide for this purpose are, however, not inconsiderable, and it was desirable to find some more suitable reference substanoe.

Whereas previously the sodium hydroxide had served both as agent for salting out and as reference substance, the attempt was now made to use a small quantity of an easily analysed electrolyte as reference substance in the presence of a large amount of another electrolyte used to salt out the soap. Sodium sulphate was found to be fairly satisfactory, but only in the presence of a concentrated solution of another salt.

EXPEIM N TAL.

The soap systems, mixtures of curd with excess of motherliquor, were all prepared in tubes of pure silver in the manner described by McBain and Taylor (Zeitsch. physikal. Chem., 1911, 76, 199). They were shaken for many weeks at temperatures between $90^{\circ}$ and $100^{\circ}$ in the hope of ensuring complete reaction, and then placed in a thermostat at $30^{\circ}$ for a few days in order that the hydration should adjust itself to this temperature. However, six years later, Miss Laing (T., 1920, 117, 1506) showed that the solubility of the curd fibres requires weeks or months to adjust itself completely to changed conditions, so that the results here 
described probably refer in some cases to a temperature considerably above $30^{\circ}$. This, however, as we now know, cannot influence the degree of hydration by more than 10 per cent. as a maximum.

In some cases the curd was made by adding together palmitic acid, sodium hydroxide solution, sodium chloride, and water in calculated amounts, but it was found that local incrustations with hard curd prevented interaction in the time allowed. This was finally avoided by first making up the solution of sodium palmitate and afterwards salting it out and leaving it during several weeks at $90^{\circ}$. In all cases, Kahlbaum's purest materials and sodium hydroxide from sodium drippings, free from carbon dioxide, were employed. Upon opening the tube the contents were filtered through silver gauze at $30^{\circ}$, the filtrate being referred to throughout this paper as mother-liquor. Specimens of both mother-liquor and curd wet with mother-liquor were submitted to complete analysis, the chloride and sulphate being estimated gravimetrically as silver chloride and barium sulphate respectively. A number of different procedures were employed for this purpose, and in some cases separate samples were used for the different estimations; water was always estimated by difference. The method of calculation of the hydration has previously been described (loc. cit.).

The data of the experiments in which $1.0 \mathrm{~N}$-sodium palmitate was salted out by saturated or nearly saturated sodium chloride solution in the presence of a small amount of sodium sulphate are given in Table I. Two experiments in which $1 \cdot 0 \mathrm{~N}$-sodium palmitate was salted out by $2 \cdot 0 \mathrm{~N}$-sodium hydroxide in the presence of a small quantity of sodium chloride are recorded in Table II. Two experiments in which the sodium chloride was only one-third saturated and sodium sulphate was used as reference substance are given in Table III ; here the composition of the inother-liquor and the hydration of the curd were deduced from the analysis and total weight of the curd.

TABLE I.

Original charge $1 \cdot 0 \mathrm{~N} \cdot \mathrm{NaP}$.

Grams per 100 grams of $\mathrm{H}_{2} \mathrm{O}$

No. of

expt. $\mathrm{NaCl}$. $\mathrm{Na}_{2} \mathrm{SO}_{4}$.

7
$33 \cdot 49$

\begin{tabular}{l}
8 \\
\hline
\end{tabular}

$11 \quad 32 \cdot 62$

$13 \quad 24 \cdot 08$

$15 \quad 24 \cdot 08$

$$
1 \cdot 84
$$

$1 \cdot 82$

$1 \cdot 250$

1.897

$\mathbf{1} \cdot 897$
Mother-liquor analysis.

Grams per 100 grams of $\mathrm{H}_{2} \mathrm{O}$
Hydration.

Mols. $\mathrm{H}_{2} \mathrm{O}$ to $\mathrm{INaP}$.

$\begin{array}{cc}\text { NaCl. } & \mathrm{Na}_{2} \mathrm{SO}_{4} . \\ 0.17 & 2 \cdot 14 \\ 0.55 & 1.79 \\ 0.96 & 2.49 \\ 0.63 & 1.62 \\ ? & 1.83\end{array}$


THE FIBRES OF SOAP CURD. PART I.

Table II.

Charge 1.0N-NaP.

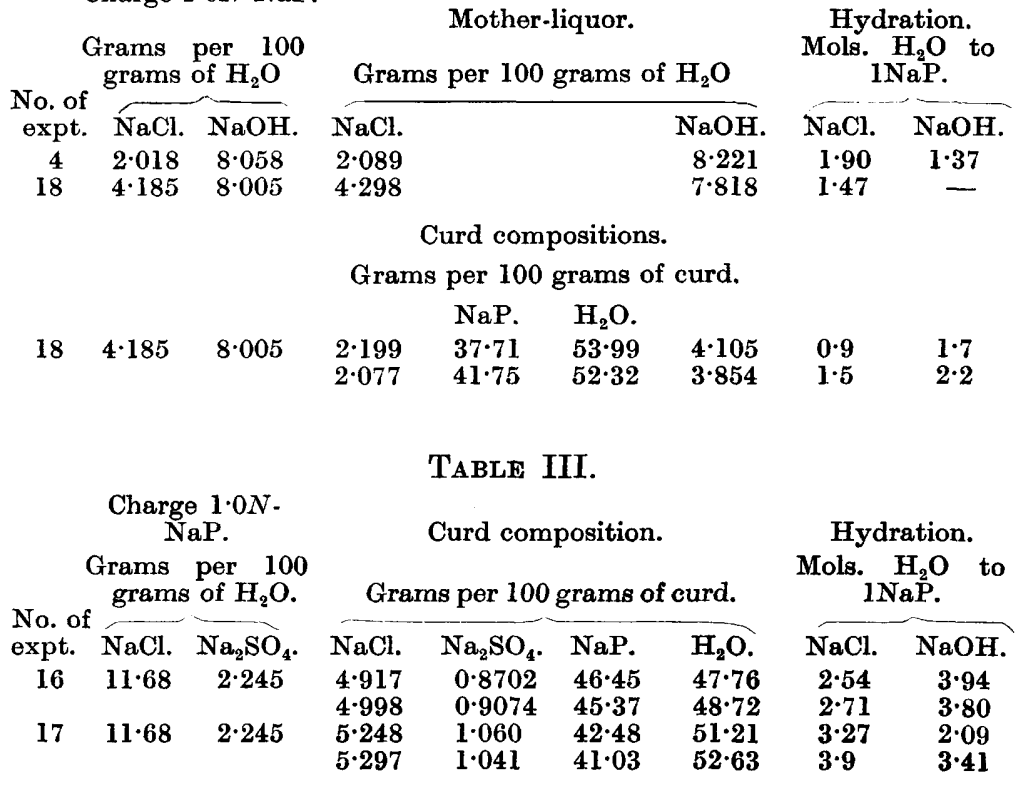

Discussion of the Results.

(a) Hydrolysis of Soap on Salting Out.

It will be seen from Experiments 8, 11, 15, 16, and 17 that when a normal solution of neutral sodium palmitate is salted out with sodium chloride of concentrations ranging from one-third to complete saturation, the mother-liquor is alkaline to the extent of only $0.002-0.004 \mathrm{~N}$-sodium hydroxide. In other words, soap salted out with neutral sodium chloride contains an amount of sodium which is within $99 \cdot 6-99 \cdot 8$ per cent. of that required exactly to neutralise the fatty acid present. Practical soap-boilers frequently assert that it is necessary to salt out soaps in the presence of an excess of alkali if appreciable hydrolysis is to be avoided. It now appears, however, most probable that acid soaps, which are undoubtedly often observed in large-scale experiments, arise from incomplete saponification. It will be shown in another communication from this laboratory that the final stages of saponification with alkali are surprisingly slow, but that if sufficient time is allowed it is completed to within 99.8 per cent. even when no excess of alkali is present. 
The measurements here given show that the hydrolysis of soap curd is slightly greater than that of the same soap in solution (McBain and Martin, T., 1914, 105, 957; McBain and Bolam, ibid., 1918, 113, 825). However, the soap fibres are, within a few tenths of a per cent., neutral soap together with water of hydration. Even when salted out by $2 \cdot 0 \mathrm{~N}$-sodium hydroxide, the curd fibres are neutral to within 0.5 per cent.

\section{(b) Hydration Values in Presence of Saturated Sodium Chloride.}

In Table $I$ there are three final results with a mean value of $2 \cdot 1$ mols. of $\mathrm{H}_{2} \mathrm{O}$ to $1 \mathrm{~mol}$. of $\mathrm{NaP}$. This is from its nature necessarily a minimum value for the hydration, since it is based on the assumption that no sodium sulphate is sorbed by the curd fibres in these circumstances. Occurrence of sorption would lessen the increase in the concentration of the sodium sulphate in the motherliquor. The value $2 \cdot 1$ mols. of $\mathrm{H}_{2} \mathrm{O}$ is probably not greatly in error, as will be seen in Part II.

\section{(c) The Sorption of Sodium Chloride by Curd Fibres.}

In Table $I$ there are three values for the hydration of curd fibres salted out by saturated solution of sodium chloride deduced from the sodium chloride itself, that is, if we ignore the sorption of sodium chloride. These are $0.2,0.6$, and 1.0 instead of 2.0 mols. of $\mathrm{H}_{2} \mathrm{O}$ to $1 \mathrm{~mol}$. of NaP. From this deficiency we can deduce the amount of salt sorbed by the sodium palmitate. It is approximately 8.9 grams of $\mathrm{NaCl}$ to $1 \mathrm{~mol}$. (278 grams) of $\mathrm{NaP}$; that is, 3.2 per cent. of the weight of the anhydrous sodium palmitate or 2.7 per cent. of the total weight of the curd fibres apart from enmeshed mother-liquor.

In the presence of $2 \cdot 0 \mathrm{~N}$-alkali, 2 per cent. sodium chloride indicated a hydration value of 1.5 and 1.9 , whereas it was previously shown (loc. cit) that the hydration is about $4 \cdot 0$ and 4.6 mols. of $\mathrm{H}_{2} \mathrm{O}$ to $1 \mathrm{~mol}$. of $\mathrm{NaP}$. The deficiency here indicates that 1.8 and 0.10 grams of sodium chloride are sorbed by $1 \mathrm{~mol}$. of $\mathrm{NaP}$ from 4 and 2 per cent. solutions of sodium chloride respectively in the presence of $2.0 \mathrm{~N}$-sodium hydroxide or 0.5 and 0.3 per cent. of the total weight of the curd fibres themselves.

Commercial soap contains about 30 per cent. of water. The wet curds of sodium palmitate were more than half water, but of course it would have been easy so to press and drain out just sufficient enmeshed brine to bring the total water contained in them 
down to 30 grams per 100 grams of curd. Had this been done with the three curds mentioned in the foregoing paragraphs, their empirical composition would have been represented by the formulæ $\mathrm{NaP}+6 \cdot 6 \mathrm{H}_{2} \mathrm{O}+0.59 \mathrm{NaCl} ; \mathrm{NaP}+6 \cdot 6 \mathrm{H}_{2} \mathrm{O}+0.063 \mathrm{NaCl}+$ $0.094 \mathrm{NaOH} ; \mathrm{NaP}+6.6 \mathrm{H}_{2} \mathrm{O}+0.029 \mathrm{NaCl}+0.07 \mathrm{NaOH}$. On the other hand, the curd fibres proper contained in these curds have the composition $\mathrm{NaP}+2 \cdot 1 \mathrm{H}_{2} \mathrm{O}+0 \cdot 15 \mathrm{NaCl} ; \mathrm{NaP}+4 \mathrm{H}_{2} \mathrm{O}+0 \cdot 031 \mathrm{NaCl}$, and $\mathrm{NaP}+4 \cdot 6 \mathrm{H}_{2} \mathrm{O}+0 \cdot 017 \mathrm{NaCl}$.

It will be seen that the proportion of sodium chloride which is free in solution in the enmeshed brine is approximately $\frac{3}{4}, \frac{1}{2}$, and $\frac{3}{7}$ respectively, the remainder being bound in the curd fibres themselves which are in equilibrium with these brines, lyes, or motherliquors. It is evident that, by washing, the greater part of the sodium chloride can be removed from the curd as well as from the curd fibres, although in accordance with the behaviour characteristic of sorption the last traces of salt in the curd fibres could never be extracted. Such washing would have to be done by "pickling," a wholly different operation from the washing " changes" involved in the soap-boiling processes which will be discussed in another communication (compare 4th Report on Colloid Chemistry, 1921).

\section{(d) Unsaturated Brine and Adsorption of Sodium Sulphate.}

From a consideration of the results in Table III, and, to a minor extent, experiments 13 and 15, it appears probable that sodium sulphate, like sodium chloride, can be sorbed by curd fibres unless this is prevented by the presence of a great excess of some other electrolyte. It is probable that in the experiments recorded in Table III, where the salting out is effected by much less concentrated sodium chloride, the true hydration of the curd fibres is at least 4.5 mols. of water to $1 \mathrm{~mol}$. of sodium palmitate, whereas the results from the analysis of sodium sulphate give a value 3.3 and those from sodium chloride indicate $3 \cdot 1$. It has already been shown that the sodium chloride is sorbed to a slight extent; here, evidently, the sodium sulphate is sorbed nearly as much, thereby interfering with the full development of the sorption of the sodium chloride. Even sodium hydroxide is affected by sorption, as will be shown in Part III, although to a very minor extent; evidently no ordinary salt is quite satisfactory as reference substance.

The only available data for the various commercial fats and oils are those of Merklen. Using his analytical data for sodium chloride and hydroxide, we deduce hydration values lying between 3.4 and 5.0 mols. of water to 1 mol. of soap in the presence of graining lye (Lessive de cuisson, Siedelauge). 


\section{Summary.}

1. When sodium palmitate is salted out with nearly saturated solutions of sodium chloride containing a small amount of sodium sulphate the increase in concentration of the sodium sulphate corresponds with a hydration of the neutral curd fibres $\mathrm{NaP}, 2 \cdot 1 \mathrm{H}_{2} \mathrm{O}$.

2. Sodium chloride is appreciably sorbed by the curd fibres, although even in this case distinct negative sorption is observed.

3. Sodium sulphate, sodium chloride, and, to a very slight extent, sodium hydroxide are each sorbed by the curd fibres except in the presence of a large excess of a second salt. Thus the empirical composition of curd fibres salted out by a saturated solution of sodium chloride corresponds with the proportions $\mathrm{NaP}: 2 \cdot 1 \mathrm{H}_{2} \mathrm{O}: 0 \cdot 16 \mathrm{NaCl}$; that is, the fibres themselves contain 78.7 per cent. of anhydrous fatty acid and about 3 per cent. by weight of sodium chloride. From more dilute lyes more water and much less salt is sorbed.

In conclusion, we have pleasure in thanking the Colston Research Society of the University of Bristol for the grants towards the purchase of materials and apparatus.

The Chemicat Defpartment, BRISTOL UNIVERSTTY.

[Received, June 7th, 1921.] 